\title{
Comunicação
}

[Communication]

\section{Espondilolistese em frango de corte no Brasil}

\author{
[Spondylolisthesis ("Kinky Back”) in broiler chickens in Brazil] \\ T.A. Paixão ${ }^{1}$, B.R.C. Ribeiro ${ }^{2}$, F.J. Hoerr ${ }^{3}$, R.L. Santos ${ }^{1 *}$ \\ ${ }^{1}$ Escola de Veterinária - UFMG \\ Caixa Postal 567 \\ Belo Horizonte, MG \\ ${ }^{2}$ Médico veterinário autônomo \\ ${ }^{3}$ College of Veterinary Medicine, Auburn University, Alburn, EUA
}

\begin{abstract}
Alterações locomotoras, com vários graus de intensidade, são freqüentemente observadas em frangos de corte na atualidade. Essas afecções podem resultar em diminuição do bem-estar das aves (European..., 2000) e perdas econômicas significativas devido à diminuição no desempenho produtivo, aumento na taxa de mortalidade e aumento da condenação das carcaças (Riddell, 1981; Sullivan, 1994).
\end{abstract}

A etiologia de problemas locomotores em frangos de corte é complexa e envolve vários fatores que podem favorecer o aparecimento dos sinais clínicos. As afecções de origem não infecciosa, entre elas a espondilolistese, são responsáveis por grande parte dos prejuízos causados por problemas locomotores na avicultura (Riddell, 1981).

Espondilolistese é uma deformidade que, de acordo com a nomenclatura atual (Hogg, 1984), afeta a quarta vértebra torácica de frangos de corte, resultando em compressão da medula espinhal e, conseqüentemente, paralisia dos membros pélvicos. Essa condição, também conhecida na indústria avícola como kinky back, acomete frangos de corte entre três a seis semanas de idade (Osbaldiston e Wise, 1967; Wise, 1970). A incidência da espondilolistese, que pode chegar a $2 \%$ na granja, depende de três fatores: idade (Osbaldiston e Wise, 1967; Wise, 1970), taxa de crescimento rápido (Wise, 1973) e genética (Osbaldiston e Wise 1967; Riddell, 1973; Wise, 1973).

A espondilolistese, inicialmente descrita em 1964, tem apresentado incidência crescente em toda a indústria avícola e já foi diagnosticada em frangos de corte da Inglaterra (Osbaldiston e Wise, 1967; Wise, 1970), Austrália (Kelly, 1971), Canadá (Riddell e Howell, 1972; Riddell e Springer, 1985) e Estados Unidos (Khan et al., 1973). De acordo com a literatura pesquisada, este é o primeiro relato de espondilolistese em frangos de corte na indústria avícola brasileira.

Foram enviadas ao setor de patologia oito aves, de ambos os sexos, com 28 dias de idade, provenientes de um lote de 35.000 frangos, criadas em uma granja comercial. As aves apresentaram crescimento rápido nas três primeiras semanas de idade, sendo a incidência de problemas locomotores de, aproximadamente, $1 \%$ na granja de origem. As aves apresentaram inicialmente incoordenação motora, caracterizada por dificuldade de locomoção que evoluiu para deslocamento lateral, cranial ou caudal de um dos membros e, posteriormente, permaneciam em decúbito lateral ou apoiadas sobre a articulação tibiotarsometatársica (Fig. 1). As aves examinadas apresentavam graus variáveis de desidratação e emaciação ou caquexia. 


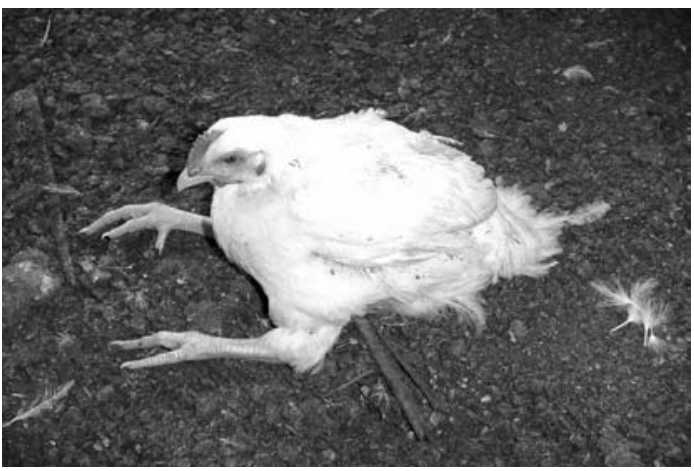

Figura 1. Frango em decúbito apoiado sobre a articulação tibiotarsometatársica com deslocamento cranial dos membros e pés suspensos ao ar, postura característica de animais acometidos por espondilolistese.

As aves foram necropsiadas e, ao exame macroscópico apresentavam emaciação e desvio anormal da coluna vertebral. As colunas vertebrais de duas aves foram dissecadas para avaliação radiográfica e, posteriormente, fixadas em formol a $10 \%$ e secionadas sagitalmente ao longo do canal vertebral para avaliação macroscópica e exame histológico.

Ao exame macroscópico do corte sagital da coluna vertebral, observou-se a quarta vértebra torácica direcionada dorsocaudalmente em relação à quinta, que apresentava a porção cranial deslocada dorsalmente. Observou-se também protusão da extremidade caudal do corpo da quarta vértebra torácica e da extremidade cranial do corpo da quinta, para o interior do canal vertebral, resultando em compressão da medula espinhal (Fig. 2).

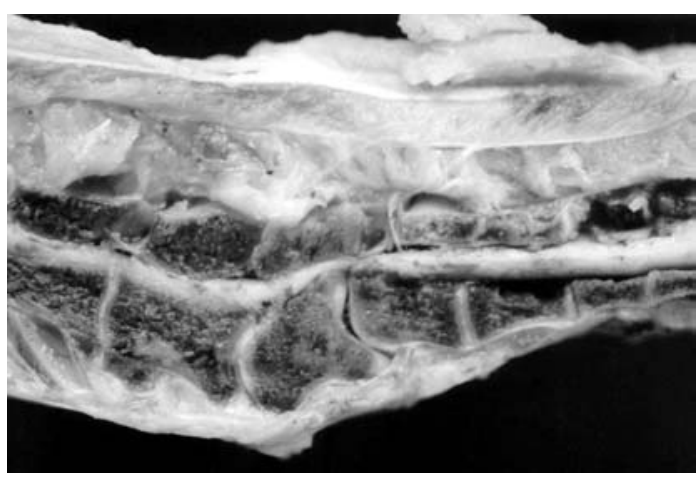

Figura 2. Corte sagital da região toracolombar da coluna vertebral de um frango de corte (craniocaudal da direita para esquerda). Quarta vértebra torácica direcionada dorsocaudalmente em relação à quinta. Protrusão das extremidades dos corpos vertebrais da sexta e sétima vértebras torácicas para o interior do canal vertebral com compressão da medula espinhal.
Radiologicamente, observou-se desalinhamento entre as colunas torácica e lombar, com deformidade da sexta vértebra torácica, caracterizada por deslocamento dorsal da extremidade caudal do corpo vertebral. Essa alteração de posicionamento vertebral estava associada com aumento da radiopacidade da metade caudal do corpo vertebral da sexta e da extremidade cranial do corpo vertebral da sétima vértebra torácica (Fig. 3).

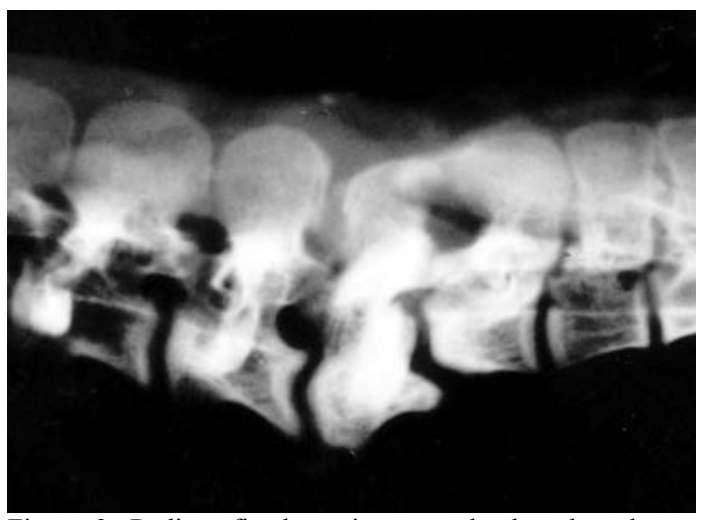

Figura 3. Radiografia da região toracolombar da coluna vertebral de frango de corte (craniocaudal da direita para esquerda). Desalinhamento entre as colunas torácica e lombar com deslocamento dorsal da extremidade caudal do corpo vertebral da quarta vértebra torácica. Aumento da radiopacidade da metade caudal do corpo vertebral da quarta e da extremidade cranial do corpo vertebral da quinta vértebra torácica.

Histologicamente, observou-se necrose focal na porção dorsal da cartilagem articular cranial do corpo vertebral da sétima vértebra torácica, associada à fibrose e retenção de ilhas de cartilagem não erodidas, lesões sugestivas de osteonecrose (Fig. 4). Na porção ventral do corpo vertebral da sétima vértebra torácica havia osteopetrose discreta caracterizada pela formação de trabéculas ósseas espessas e contínuas, com intensa hiperplasia osteoblástica, correspondendo à área de aumento de radiopacidade na radiografia (Fig. 5). Em uma das aves observouse degeneração moderada difusa do músculo espinhal. Em ambas as aves, havia infiltrado inflamatório linfocitário perivascular moderado e restrito à dura-máter. A medula espinhal apresentou perda completa dos neurônios no ponto de compressão, poucos balões axonais no segmento cranial e grande número de balões axonais e câmaras de digestão no segmento caudal caracterizando degeneração walleriana. 


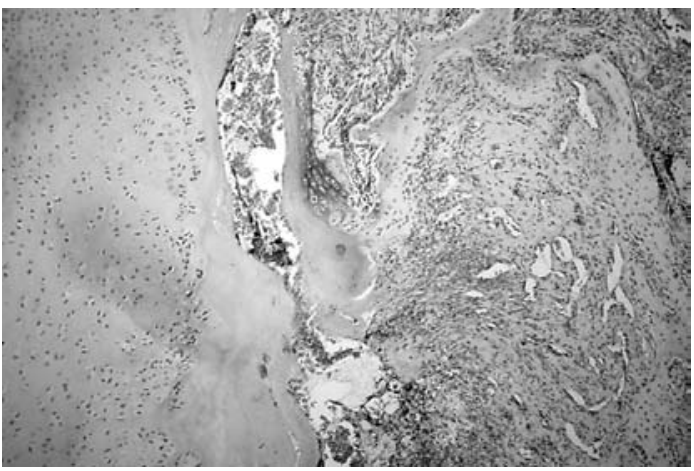

Figura 4. Quinta vértebra torácica de um frango de corte. Necrose focal da cartilagem articular cranial, com intensa fibroplasia adjacente substituindo as trabéculas ósseas. HE, 100X.

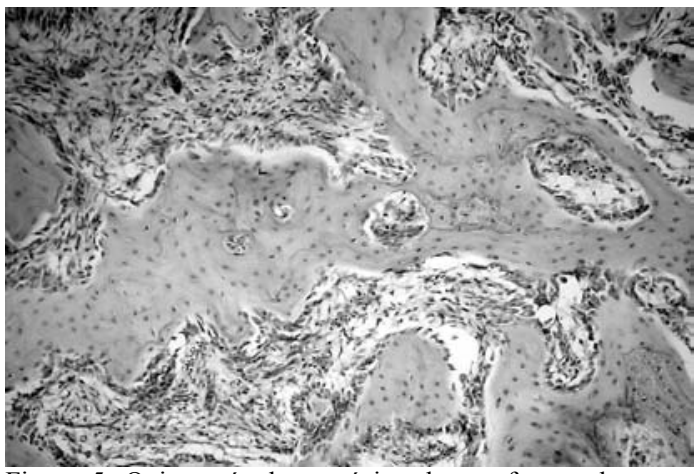

Figura 5. Quinta vértebra torácica de um frango de corte. Trabéculas ósseas espessas e contínuas com hiperplasia osteoblástica, caracterizando osteopetrose. HE, 200X.

A espondilolistese acomete somente frangos de corte na idade de uma a nove semanas, sendo mais freqüente entre três a seis semanas de idade, sem predisposição por sexo (Wise, 1970). Neste trabalho foi observado o problema em frangos com quatro semanas de idade.

A manifestação clínica mais comum foi a paraplegia, com as aves apoiadas sobre a cauda ou sobre as articulações tibiotarsometatársicas com os pés suspensos no ar. Em casos avançados, as aves encontravam-se em decúbito lateral. A morte nos casos de espondilolistese é conseqüência de desidratação e inanição devido à impossibilidade de acesso à água e ração (Wise, 1970). Segundo Wise (1970), em granjas com espondilolistese clínica, observam-se casos subclínicos com apenas a manifestação de claudicação ocasional em algumas aves, embora na maioria dos casos subclínicos as aves apresentam-se completamente normais.
Aparentemente, espondilolistese é uma condição progressiva em que casos subclínicos de distorção da coluna podem ou não evoluir para estenose e compressão medular com manifestação de sinais neurológicos. No presente relato, não foi possível avaliar a freqüência de espondilolistese subclínica devido à restrição de amostragem.

Como descrito neste caso, macroscopicamente e radiograficamente, o que se observa na espondilolistese é um deslocamento dorsal do corpo vertebral da sexta e sétima vértebras torácicas. Wise (1970) considera essa deformação somente uma alteração na direção do crescimento ósseo, sem haver alteração na quantidade ou qualidade do osso. Além disso, geralmente não se observa alteração de ligamentos e nem de musculatura. Contudo, neste caso, foram observadas alterações nas vértebras compatíveis com osteonecrose e, em uma das aves, degeneração da musculatura adjacente à coluna vertebral como descrito por Khan et al. (1973; 1977). Dammrich e Heitman (1994) sugeriram que a osteonecrose pode ocasionar artropatia deformante nas vértebras devido a instabilidade da quarta vértebra torácica em aves com espondilolistese. Apesar de a osteocondrose ser freqüentemente observada nos corpos vertebrais não está claro a relação de causa e efeito entre a osteocondrose e a espondilolistese. Contudo, a alta incidência dessas duas alterações pode estar associada ao distúrbio de crescimento ósseo no frango de corte (Duff, 1990).

Nas condições de clima tropical de altitude, a ocorrência de espondilolistese aparentemente é maior durante os meses de outono e inverno, quando a temperatura ambiente baixa proporciona condição ideal para melhor conversão alimentar e crescimento rápido. Segundo Wise (1973), a incidência de espondilolistese pode ser diminuída com o retardamento do crescimento precoce dos frangos (Wise, 1973). O estresse físico anormal, o distúrbio nutricional e fatores genéticos são considerados como importantes causas ou fatores predisponentes dessa espondilopatia (Wise, 1973; Riddell, 1973; Riddell e Howell, 1972).

Os achados anatomopatológicos e radiológicos das oito aves estudadas são compatíveis com o diagnóstico de espondilolistese. Este parece ser o primeiro relato de espondilolistese em frango de corte no Brasil.

Palavras-chave: frango de corte, espondilolistese, paraplegia, coluna vertebral 


\begin{abstract}
Eight 28-day-old broiler chickens of both sexes were examined. Clinical signs, gross findings, radiological, and histopathological changes were described. Spondylolisthesis was characterized by dorsal displacement of the sixth and seventh thoracic vertebrae, resulting in compression of the spinal cord. The major clinical manifestation was paraplegia. Risk factors such as genetics, nutrition, stress, rate of growth, and age were discussed.
\end{abstract}

Keywords: broiler chicken, spondylolisthesis, kinky back, paraplegia, vertebral column

\section{REFERENCES}

\section{DAMMRICH, K.; HEITMANN, K. Osteochondrose-syndrom und arthropathia deformans als ursache der habituellen und stationären luxatio incompleta des 6 . brustwirbels bei legehennen mit paralyse. Berlin. Münch. Tierärzt. Wochenschr., v.107, p.218-25, 1994.}

DUFF, S.R.I. Do different forms of spondylolisthesis occur in broiler fowls? Avian Pathol., v.19, p.279-294, 1990.

EUROPEAN COMMISSION. The welfare of chickens kept for meat production. Report of the

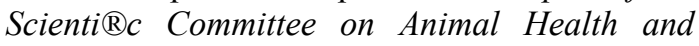
Animal Welfare. 2000.

HOGG, D.A. The distribuition of pneumatisation in the skeleton of the adult domestic fowl. $J$. Anat., v. 138, p.617-629, 1984.

KELLY, W.R. Occurrence of spondylolisthesis ("Kinky Back") in broiler chickens in south Australia. Aust. Vet. J., v.47, p.73, 1971.

KHAN, M.A.; OLSON, N.O.; OVERMAN, D.O. Spontaneous spondylolisthesis in embryonic e adult chick. Poult. Sci., v.56, p.689-697, 1977.

KHAN, M.A.; OLSON, N.O.; WEISS, R. Spondylopathy in broilers. Case reports. Poult. Sci., v.52, p.1847-1852, 1973.
OSBALDISTON, G.W.; WISE, D.R. Spondylolisthesis and leg weakness in the chicken- a common aetiology. Vet. Rec., v.80, p.320-322, 1967.

RIDDELL C.; SPRINGER R. An epizootiological study of acute death syndrome and leg weakness in broiler chickens in western Canada. Avian Dis., v.29, p.90-102, 1985.

RIDDELL, C. Skeletal deformities in poultry. Adv. Vet. Sci. Comp. Med., v.25, p.277-310, 1981.

RIDDELL, C. Studies on spondylolisthesis ("Kinky back") in broiler chickens. Avian Pathol., v.2, p.295-304, 1973.

RIDDELL, C.; HOWELL, J. Spondylolisthesis ("Kinky back") in broiler chickens in western Canada. Avian Dis., v.16, p.444-452, 1972.

SULLIVAN, T.W. Skeletal problems in poultry: estimated annual cost and descriptions. Poult. Sci., v.73, p.879-882, 1994.

WISE, D.R. Spondylolisthesis ("Kinky back") in broiler chickens. Res. Vet. Sci., v.2, p.447-451, 1970.

WISE, D.R. The incidence and aetiology of avian spondylolisthesis ("Kinky back"). Res. Vet. Sci., v.14, p.1-10, 1973. 